\title{
ORAL MANAGEMENT IN REHABILITATION MEDICINE: ORAL FRAILTY, ORAL SARCOPENIA, AND HOSPITAL-ASSOCIATED ORAL PROBLEMS
}

\author{
A. SHIRAISHI ${ }^{1}$, H. WAKABAYASHI ${ }^{2}$, Y. YOSHIMURA ${ }^{3}$
}

\begin{abstract}
1. Center for Sarcopenia and Malnutrition Research, Kumamoto Rehabilitation Hospital, Kumamoto, Japan; 2. Dpt. of Rehabilitation Medicine, Tokyo Women's Medical University Hospital, Japan; 3. Center for Sarcopenia and Malnutrition Research, Kumamoto Rehabilitation Hospital, Kumamoto, Japan. Corresponding author: Hidetaka Wakabayashi, Dpt. of Rehabilitation Medicine, Tokyo Women's Medical University Hospital, Japan., 8-1, Kawada-cho, Shinjuku-ku, Tokyo, Japan. Code; 162-0054, Email: noventurenoglory@gmail.com, Tel: +81-3-3353-8111, FAX: +81-3-5269-7639
\end{abstract}

\begin{abstract}
Oral health is a crucial but often neglected aspect of rehabilitation medicine. Approximately $71 \%$ of hospitalized rehabilitation patients and $91 \%$ of hospitalized acute care patients have impaired oral health. Poor oral condition in hospitalized patients can be attributed to factors such as age, physical dependency, cognitive decline, malnutrition, low skeletal muscle mass and strength, and multimorbidity. Another major factor is a lack of knowledge and interest in oral problems among health care workers. Recently, new concepts have been proposed, such as oral frailty, oral sarcopenia, and hospital-associated oral problems. Oral frailty, the accumulation of a slightly poor status of oral conditions and function, strongly predicts physical frailty, dysphagia, malnutrition, need for long-term care, and mortality in community-dwelling older adults. Oral sarcopenia refers to sarcopenia associated with oral conditions and function, although its definition has not yet been fully discussed. Hospital-associated oral problems are caused by disease, disease treatment, surgery, endotracheal intubation, poor self-care abilities, lack of care by medical staff, drugs, and iatrogenic factors during hospitalization. Furthermore, oral problems have negative impacts on rehabilitation outcomes, which include functional recovery, length of hospital stay, discharge home, and in-hospital mortality. Oral health management provided by dental hygienists improves not only oral status and function, swallowing function, and nutritional status but also activities of daily living, discharge home, and in-hospital mortality in post-acute rehabilitation. Oral rehabilitation, promotion, education, and medical-dental collaboration can be effective interventions for oral problems and therefore are necessary to improve rehabilitation outcomes.
\end{abstract}

Key words: Oral health, rehabilitation, dental hygienist, medical-dental collaboration.

\section{Introduction}

Oral health is a crucial yet often neglected aspect of rehabilitation. Oral problems, or impaired oral health status, affect the rate of decline in oral function related to aging and disease, oral diseases related to lifestyle, and frailty (1-4). Moreover, the oral health-related quality of life of nursing home residents is significantly impaired (5). Recently, with the growing interest in oral management in rehabilitation, new concepts have been proposed, such as oral frailty (4), oral sarcopenia (6), and hospital-associated oral problems $(7,8)$.

Oral problems have adverse impacts on rehabilitation outcomes. Poor oral condition in hospitalized older adults can be attributed to various factors such as age, physical dependency, cognitive decline, malnutrition, low skeletal muscle mass and strength, and multimorbidity $(4,6)$. Lack of knowledge and interest in oral problems among health care workers is another important factor (9). Further, older inpatients with poor oral health on admission have poorer functional recovery, less opportunity to be discharged, and higher in-hospital mortality rates (10). Therefore, early detection of oral problems, treatment by dental professionals, education on oral management for nurses and other non-dental professionals, multidisciplinary oral rehabilitation, and medical-dental collaboration are essential. However, the evidence in oral management in rehabilitation settings is scarce and has not been fully discussed.

This review outlines the epidemiology and factors of oral problems, their relationship to outcomes, the effectiveness of interventions, and the need for medical and dental collaboration in rehabilitation medicine.

\section{Epidemiology and associated factors of oral problems}

\section{Aging}

Aging causes a decline in oral function - the number of teeth, occlusal strength, and thickness of the masseter muscle decrease (11-14). According to a survey in the US, 96.4\% of older adults aged 65 and over have periodontal disease (15). Periodontal disease is often associated with chronic diseases (16). In older adults with chronic illnesses, prescribed medications may also cause xerostomia and increase the risk of oral disease (17).

Impaired oral health, e.g. tooth loss and subjective difficulties in eating directly, leads to functional decline, frailty, and disability (11). Previous studies have reported an association between oral function and physical condition. Low masticatory ability is associated with weaker physical performance (18), sarcopenia (19), and mortality (20), whereas low tongue pressure is significantly associated with frailty in older individuals (21) and reflects dysphagia (22). In addition, low occlusal force, masseter muscle thickness, and articulatory 


\section{THE JOURNAL OF NUTRITION, HEALTH \& AGING}

oral motor skill have been cross-sectionally associated with frailty (11). Frailty increases the vulnerability for developing increased dependency and/or mortality when exposed to a stressor (23). These findings suggest that impaired oral function could be closely associated with frailty.

Recently, new concepts such as oral frailty (4) and oral sarcopenia (6) have been proposed and have gained attention. Oral frailty - the accumulation of a slightly poor status in oral conditions and function-strongly predicted physical frailty, dysphagia, malnutrition, the need for long-term care, and mortality in community-dwelling older adults (4). Oral sarcopenia refers to sarcopenia associated with oral conditions and function, but its definition has not yet been fully discussed $(2,6,24)$. These age-related concepts of «oral decline» are clinically relevant in rehabilitation settings because they represent a precursor to functional impairment, although more research is needed to determine their definitions and diagnoses.

\section{Disease}

Oral problems can be attributed to various chronic diseases. Periodontitis is a common chronic inflammatory disease characterized by the destruction of the supporting structures of the teeth (the periodontal ligament and alveolar bone). It is highly prevalent (severe periodontitis affects $10-15 \%$ of adults) and has multiple negative impacts on quality of life (25). Epidemiological data confirm that diabetes is a major risk factor for periodontitis; susceptibility to periodontitis is increased by approximately threefold in people with diabetes (26). There is a clear relationship between degree of hyperglycemia and severity of periodontitis (27). The mechanisms that underpin the links between these two conditions are not completely understood, but involve aspects of immune functioning, neutrophil activity, and cytokine biology (27). In addition, poor oral health assessed using self-report or clinical examination is related to an elevated risk of coronary heart disease (28). Mechanistic support for this relationship may be associated with increased systemic inflammatory activity, which has itself been implicated in the etiology of coronary heart disease (29). Poor oral health is also commonly found in patients with chronic kidney diseases and may contribute to protein-energy wasting, systemic inflammation, infections, and atherosclerotic complications (30). One randomized controlled study demonstrated that intensive periodontal treatment had beneficial effects on oral health, which were associated with improvement in endothelial function (31).

Sarcopenia decreases oral function. Sarcopenia, the loss of muscle mass and strength or function, occurs with aging and is recognized as an independent medical condition by the International Classification of Diseases (32). A close relationship between impaired oral function and systemic sarcopenia has been shown in stroke patients (6); the association was independent of age, sex, nutritional status, comorbidities, physical and cognitive independence, and stroke severity. Sarcopenic dysphagia is a condition characterized by sarcopenia-induced swallowing disorder and the loss of swallowing muscle mass and function (33). Four Japanese professional organizations consolidated the currently available evidence about sarcopenia and dysphagia in a position paper report in 2019 (34). In rehabilitation settings, dysphagia is independently associated with sarcopenia in patients with stroke, musculoskeletal diseases, and hospital-associated deconditioning $(35,36)$. The atrophy of swallowing muscles is associated with the severity of dysphagia in patients who experience an acute stroke (37). Furthermore, a previous report shows that skeletal muscle mass, activities of daily living (ADL), and body mass index are independent predictors of dysphagia in hospitalized older adults (38). Therefore, early detection, prevention, and improvement of sarcopenia should be one of the central roles of oral management in clinical practice.

\section{Hospital-associated oral problems}

Oral problems commonly occur, sometimes unintentionally, in hospitals, which is called "hospital-associated oral problems" (39). It is caused by disease, disease treatment, surgery, endotracheal intubation, poor self-care abilities, lack of care by medical staff, drugs, and iatrogenic factors during hospitalization. Although it is difficult to completely prevent hospital-associated oral problems caused by these conditions, iatrogenic complications can be prevented or treated. During hospitalization, oral status and function can easily deteriorate, particularly in intubated patients, leading to an increased risk of hospital-acquired infections and reduced life quality (7). There is evidence that biofilms formed on the oral surface and endotracheal tubes act as a reservoir of organisms that cause ventilator-associated pneumonia; thus, oropharyngeal decontamination and other intensive strategies aimed at preventing this translocation must be emphasized (40). Patients hospitalized in intensive care units (ICU) have a high prevalence of periodontal disease that is likely to be exacerbated (8). Although daily oral hygiene measures are an important part of the care of ICU patients, it often seems to be given a low priority by medical staff in the acute care setting (41). A survey of nursing home staff found that they tended to prioritize non-oral-care activities over oral care activities (42). Moreover, nurses and other non-dental professionals tend to be less interested in oral hygiene in post-stroke care (43).

Education and practice programs in oral health care management for medical staff are needed to prevent or treat hospital-related oral problems. Improved oral hygiene reduces the occurrence of respiratory tract diseases among older patients in the ICU (44). Moreover, approximately one out of ten cases of death from pneumonia among geriatric inpatients could be prevented by improving their oral hygiene (45). Nurses and speech-language pathologists can participate in oral rehabilitation to improve the outcome of impaired oral status (function) and dysphagia (43). Oral health knowledge was positively associated with the clinical practice of providing better oral hygiene care for patients after stroke (46). A simple, 
Figure 1

Risk factors, therapeutic interventions and rehabilitation outcomes for oral problems

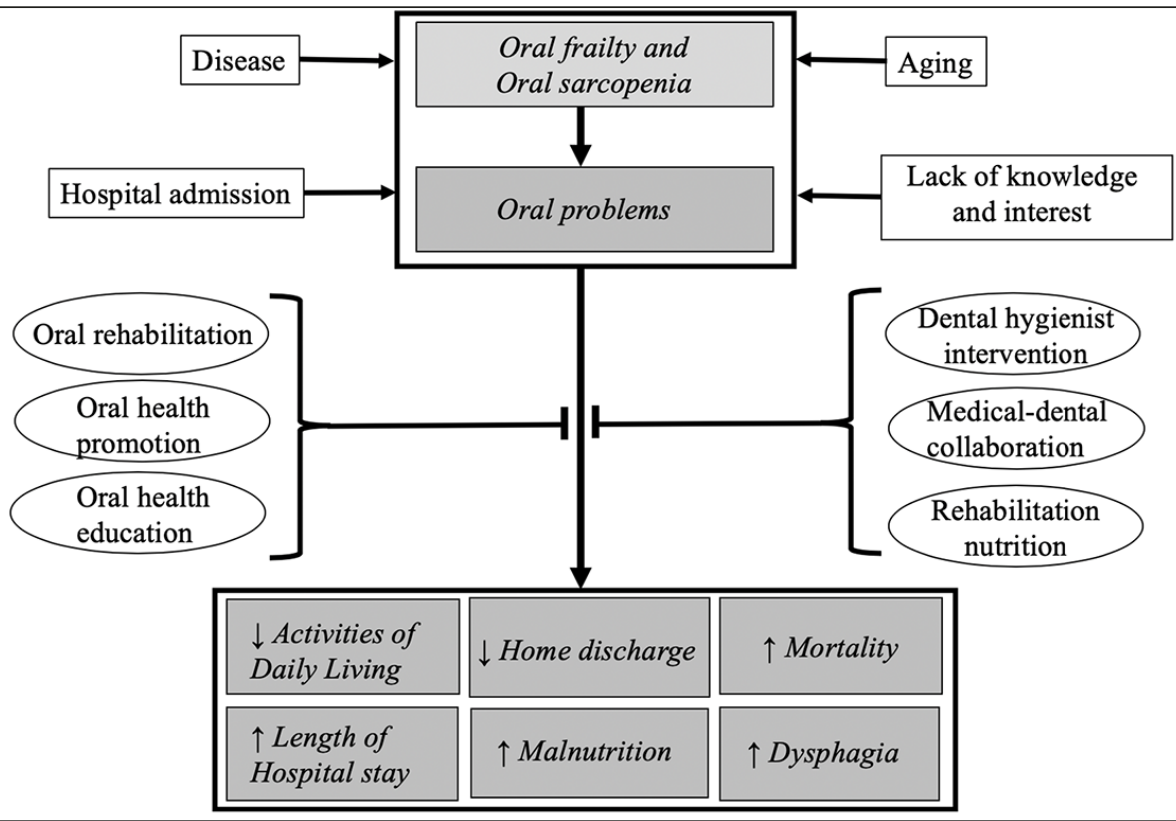

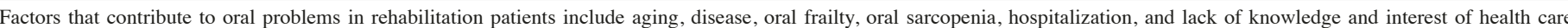

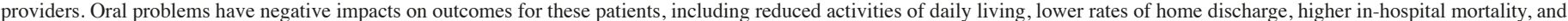

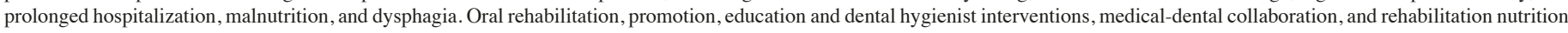
can be effective interventions for oral problems to further improve rehabilitation outcomes

inexpensive oral hygiene regimen resulted in positive outcomes for patients with and without dysphagia in inpatient stroke rehabilitation settings (47). In addition, preoperative oral care by dentists has reduced postoperative complications in patients undergoing cancer surgery (48). Therefore, oral health management needs to be improved and integrated into the carechain of hospitalized individuals. This is not only a matter of oral health but may also lead to saving patients' lives.

\section{Oral status and rehabilitation outcomes}

Oral problems are frequently found in rehabilitation. Impaired oral health status is common in hospitalized patients, particularly among physically disabled, demented, or malnourished older adults $(10,49,50)$. The proportion of hospitalized older patients with oral health problems is greater than $80 \%(10,50)$. Furthermore, $71 \%$ of hospitalized rehabilitation patients (51) and $91 \%$ of hospitalized acute care patients are reported to have impaired oral health (52).

Oral problems have negative impacts on rehabilitation outcomes. In convalescent rehabilitation inpatients, oral problems were independently associated with inpatient discharge, ADL, length of hospital stay, discharge at home, and in-hospital mortality; this association was regardless of age, sex, disease severity, nutritional status, comorbidities, and physical and cognitive dependency $(10,50)$. Poor oral status and function could have direct effects on denture wearing, dental occlusion, chewing ability, and the consequent dysphagia, which could be a major cause of malnutrition Moreover, malnutrition and dysphagia have direct effects on functional recovery (53-55). Therefore, oral problems have indirect adverse effects on ADL recovery. Furthermore, reduced self-care ability is an important factor affecting oral health in hospitalized patients. Oral health care is an important form of self-care included in subcategories of basic ADL assessment, such as Functional Independence Measure and Barthel Index. Factors contributing to reduced self-care ability may include physical dependency or disability due to aging, disease, sarcopenia, malnutrition, cognitive and psychological disorders, and socioeconomic factors. In addition, reduced ADL, dysphagia, and malnutrition indirectly caused by impaired oral health status may lead to prolongation of hospital stay among patients undergoing rehabilitation.

Oral problems are associated with physical and cognitive function. Masticatory performance is associated with handgrip strength, maximum voluntary occlusal force, and diadochokinesis (56). Tooth loss is associated with an accelerated decline in walking speed in older adults (57). Occlusal support is associated with improved nutrition, dysphagia, and ADL recovery in patients recovering from hip fractures (58) and among older adults needing long-term care (59). Improving occlusion by wearing an occlusal splint improves trunk balance and lower extremity muscle strength (60). Furthermore, oral problems are associated with cognitive decline (50). Oral health and cognitive impairment have a direct effect on denture placement, and the resulting dysphagia 


\section{THE JOURNAL OF NUTRITION, HEALTH \& AGING}

is positively associated with cognitive impairment and malnutrition (61-63). Therefore, early detection and therapeutic interventions of oral problems are essential to prevent and delay physical and cognitive decline and to improve rehabilitation outcomes.

\section{Intervention for oral problems}

Oral rehabilitation improves impaired oral status and function. Oral rehabilitation refers to rehabilitation of oral function, and it improves quality of life $(64,65)$. An oral exercise program focusing on enhancing mastication, salivation, and swallowing function was shown to effectively improve oral function (66). Prosthodontic rehabilitation increases oral health-related quality of life, orofacial esthetics, and chewing function (67). A combination of oral functional training and dietary supplements improves nutritional status in malnourished older patients in nursing homes (64). Tongue resistance training improves tongue pressure and swallowing function in stroke patients $(66,68)$. Other effective treatment options include jaw opening exercise (69), self-exercise of oral function (70), and Shaker exercise $(71,72)$, which are reported to improve swallowing function and reduce aspiration pneumonia.

Oral health promotion and education positively impact oral problems $(73,74)$. A three-month oral function promotion program improved oral function and oral health-related quality of life for older adults (75). Another similar program including facial muscle and tongue exercises and salivary gland massage was effective in improving oral health status and function in independent older adults (76). In Japan, one of the duties of the long-term care insurance system is the prevention of oral function degradation, and professionals involved in that program include nurses, speech-language pathologists, and dental hygienists (74). The effects of the Japanese «Prevention of Long-Term Care» Project was confirmed in regard to oral status and function $(73,77,78)$. However, there is currently a lack of evidence of the impact of oral promotion programs on rehabilitation outcomes.

\section{Medical-dental collaboration}

Medical-dental collaboration is crucial in rehabilitation (79). Perioperative oral function management can reduce the risk of postoperative pneumonia and is covered by health insurance in Japan. Additionally, collaboration between dental practitioners and non-dental care providers may improve oral health care for people in rural and remote areas with limited access to oral health services (80).

However, medical-dental collaboration and knowledge of oral health management are insufficient in rehabilitation and general medicine. Dentists focus on the diagnosis and treatment of oral diseases and tend to overlook general health problems. Similarly, physicians tend not to address patients' oral health issues (81). The competency level of physicians, residents, and nurses was lower than $30 \%$ for identifying tooth decay and oral pathology (9). Frequency rates for dental referral by medical providers were $32 \%$ "frequently" and 68\% "infrequently" (9). A qualitative study exploring general practitioners' and dentists' experiences and expectations of interprofessional collaboration revealed that both reported perceived knowledge deficits of the other profession (82). Moreover, most general practitioners saw no need for medical-dental collaboration, although dentists were interested in extending medical-dental collaboration (82). Medical-dental collaboration is inadequate and should be improved in rehabilitation and general medicine.

Dental hygienists can play a central role in rehabilitation collaboration. The role of dental hygienists includes screening and assessing oral health and function and providing treatment, education, and counseling in oral health management, oral and dysphagia rehabilitation, and interprofessional collaboration (83). Oral health management provided by dental hygienists improves not only oral status, swallowing function, and nutritional status, but also ADL, home discharge, and in-hospital mortality in post-acute rehabilitation (83). Therefore, early detection of oral problems, early oral health management by dentists and dental hygienists, and medicaldental collaboration should be implemented in rehabilitation. The presence of dental hygienists is indispensable for rehabilitation hospitals and rehabilitation nutrition $(83,84)$.

\section{Conclusions}

Oral health is a crucial aspect of rehabilitation. Oral problems occur frequently in rehabilitation patients and can be attributed to various factors. Health care providers need to understand and take adequate measures to prevent the onset of "hospital-associated oral problems". Furthermore, oral problems have adverse impacts on rehabilitation outcomes. Oral rehabilitation, promotion, education, and medicaldental collaboration can be effective interventions for oral problems. However, there is a lack of knowledge and interest in oral health in rehabilitation. Therefore, prevention and early detection of oral problems, multidisciplinary oral rehabilitation, and the promotion of medical and dental collaboration are necessary to improve rehabilitation outcomes.

Acknowledgments: This work was supported by a grant from JSPS KAKENHI Grant Number $19 \mathrm{H} 03979$.

Disclosure statement: Hidetaka Wakabayashi reports grants from JSPS KAKENHI Grant Number 19H03979, during the conduct of the study.

Conflict of interest: Ai Shiraishi, Hidetaka Wakabayashi, and Yoshihiro Yoshimura have nothing to disclose.

Ethical Standards: This study has been performed in accordance with the ethical standards estabilished in the 1964 Declaration of Helsinki and later amendments.

\section{References}

1. Wong FMF, Ng YTY, Keung Leung W. Oral health and its associated factors among older institutionalized residents - a systematic review. Int J Environ Res Public Health. 2019;16:4132. doi:10.3390/ijerph16214132 


\section{ORAL MANAGEMENT IN REHABILITATION MEDICINE}

2. Azzolino D, Passarelli PC, De Angelis P, Piccirillo GB, D’Addona A, Cesari M Poor Oral Health as a Determinant of Malnutrition and Sarcopenia. Nutrients. 2019;11:2898. doi:10.3390/nu11122898

3. Bloom I, Lawrence W, Barker M, et al. What influences diet quality in older people? A qualitative study among community-dwelling older adults from the Hertfordshire Cohort Study, UK. Public Health Nutr. 2017;20:2685-2693. doi:10.1017/ S1368980017001203

4. Tanaka T, Takahashi K, Hirano H, et al. Oral Frailty as a Risk Factor for Physica Frailty and Mortality in Community-Dwelling Elderly. J Gerontol A Biol Sci Med Sci. 2018;73:1661-1667. doi:10.1093/gerona/glx225/4638577

5. Klotz AL, Hassel AJ, Schröder J, Rammelsberg P, Zenthöfer A. Oral health-related quality of life and prosthetic status of nursing home residents with or without dementia. Clin Interv Aging. 2017;12:659-665. doi:10.2147/CIA.S125128

6. Shiraishi A, Yoshimura Y, Wakabayashi H, Tsuji Y. Prevalence of stroke-related sarcopenia and its association with poor oral status in post-acute stroke patients: Implications for oral sarcopenia. Clin Nutr. 2018;37:204-207. doi:10.1016/j. clnu.2016.12.002

7. Terezakis E, Needleman I, Kumar N, Moles D, Agudo E. The impact of hospitalization on oral health: A systematic review. J Clin Periodontol. 2011;38:628636. doi:10.1111/j.1600-051X.2011.01727.x

8. Araújo MM, Albuquerque BN, Cota LOM, Cortelli SC, Cortelli JR, Costa FO. Periodontitis and Periodontopathogens in Individuals Hospitalized in the Intensive Care Unit: A Case-Control Study. Braz Dent J. 2019;30:342-349. doi:10.1590/0103 6440201902480

9. Shimpi N, Schroeder D, Kilsdonk J, et al. Medical Providers' Oral Health Knowledgeability, Attitudes, and Practice Behaviors: An Opportunity for Interprofessional Collaboration. J Evid Based Dent Pract. 2016;16:19-29. doi:10.1016/j.jebdp.2016.01.002

10. Shiraishi A, Yoshimura Y, Wakabayashi H, Tsuji Y, Shimazu S, Jeong S. Impaired oral health status on admission is associated with poor clinical outcomes in post-acute inpatients: A prospective cohort study. Clin Nutr. 2019;38:2677-2683. doi:10.1016/j. clnu.2018.11.020

11. Watanabe $\mathrm{Y}$, Hirano H, Arai H, et al. Relationship Between Frailty and Ora Function in Community-Dwelling Elderly Adults. J Am Geriatr Soc. 2017;65:66-76. doi:10.1111/jgs.14355

12. Horibe Y, Ueda T, Watanabe Y, et al. A 2-year longitudinal study of the relationship between masticatory function and progression to frailty or pre-frailty among community-dwelling Japanese aged 65 and older. J Oral Rehabil. 2018;45:864-870. doi:10.1111/joor.12700

13. Ramsay SE, Papachristou E, Watt RG, et al. Influence of Poor Oral Health on Physical Frailty: A Population-Based Cohort Study of Older British Men. J Am Geriatr Soc. 2018;66:473-479. doi:10.1111/jgs.15175

14. Kamdem B, Seematter-Bagnoud L, Botrugno F, Santos-Eggimann B. Relationship between oral health and Fried's frailty criteria in community-dwelling older persons. BMC Geriatr. 2017;17:174. doi:10.1186/s12877-017-0568-3

15. Eke PI, Dye BA, Wei L, et al. Update on Prevalence of Periodontitis in Adults in the United States: NHANES 2009 to 2012. J Periodontol. 2015;86:611-622. doi:10.1902/ jop.2015.140520

16. Haque M, Sartelli M, Haque SZ. Dental infection and resistance-global health consequences. Dent J. 2019;7:22. doi:10.3390/dj7010022

17. Raphael C. Oral health and aging. Am J Public Health. 2017;107:S44-S45 doi:10.2105/AJPH.2017.303835

18. Iinuma T, Arai Y, Fukumoto M, et al. Maximum occlusal force and physical performance in the oldest old: The Tokyo oldest old survey on total health. J Am Geriatr Soc. 2012;60:68-76. doi:10.1111/j.1532-5415.2011.03780.x

19. Murakami M, Hirano H, Watanabe Y, Sakai K, Kim H, Katakura A. Relationship between chewing ability and sarcopenia in Japanese community dwelling older adults. Geriatr Gerontol Int. 2015;15:1007-1012. doi: 10.1111/ggi.12399

20. Iinuma T, Arai Y, Takayama M, et al. Association between maximum occlusal force and 3-year all-cause mortality in community-dwelling elderly people. BMC Oral Health. 2016;16. doi:10.1186/s12903-016-0283-z

21. Tsuga K, Yoshikawa M, Oue H, et al. Maximal voluntary tongue pressure is decreased in Japanese frail elderly persons. Gerodontology. 2012;29:e1078-e1085. doi:10.1111/ j.1741-2358.2011.00615.x

22. Yoshida M, Kikutani T, Tsuga K, Utanohara Y, Hayashi R, Akagawa Y. Decreased tongue pressure reflects symptom of dysphagia. Dysphagia. 2006;21:61-65. doi:10.1007/s00455-005-9011-6

23. Dent E, Morley JE, Cruz-Jentoft AJ, et al. Physical Frailty: ICFSR International Clinical Practice Guidelines for Identification and Management. J Nutr Health Aging. 2019;23:771-787. doi:10.1007/S12603-019-1273-Z

24. Kobuchi R, Okuno K, Kusunoki T, Inoue T, Takahashi K. The relationship between sarcopenia and oral sarcopenia in elderly people. J Oral Rehabil. 2020;47:636-642. doi:10.1111/joor.12948

25. Chee B, Park B, Bartold PM. Periodontitis and type II diabetes: A two-way relationship. Int J Evid Based Healthc. 2013;11(4):317-329. doi:10.1111/1744 1609.12038

26. Preshaw PM, Bissett SM. Periodontitis and diabetes. Br Dent J. 2019;227:577-584 doi:10.1038/s41415-019-0794-5

27. Jepsen S, Suvan J, Deschner J. The association of periodontal diseases with metabolic syndrome and obesity. Genco R, ed. Periodontol 2000. 2020;83:125-153. doi:10.1111/ prd. 12326

28. Batty GD, Jung KJ, Mok Y, et al. Oral health and later coronary heart disease: Cohort study of one million people. Eur J Prev Cardiol. 2018;25:598-605. doi:10.1177/2047487318759112

29. Davé S, Van Dyke TE. The link between periodontal disease and cardiovascular disease is probably inflammation. Oral Dis. 2008;14:95-101. doi:10.1111/j.16010825.2007.01438.x

30. Akar H, Akar GC, Carrero JJ, Stenvinkel P, Lindholm B. Systemic consequence of poor oral health in chronic kidney disease patients. Clin J Am Soc Nephrol. 2011;6:218-226. doi:10.2215/CJN.05470610

31. Tonetti MS, D'Aiuto F, Nibali L, et al. Treatment of periodontitis and endothelial function. N Engl J Med. 2007;356:911-920. doi:10.1056/NEJMoa063186

32. Cao L, Morley JE. Sarcopenia Is Recognized as an Independent Condition by an International Classification of Disease, Tenth Revision, Clinical Modification (ICD-10-CM) Code. J Am Med Dir Assoc. 2016;17:675-677. doi:10.1016/j. jamda.2016.06.001

33. Mori T, Fujishima I, Wakabayashi H, et al. Development, reliability, and validity of a diagnostic algorithm for sarcopenic dysphagia. JCSM Clin Reports. 2017;2:1-10. doi:10.17987/jcsm-cr.v2i2.17

34. Fujishima I, Fujiu-Kurachi M, Arai H, et al. Sarcopenia and dysphagia: Position paper by four professional organizations. Geriatr Gerontol Int. 2019;19:91-97. doi:10.1111/ ggi.13591

35. Yoshimura Y, Wakabayashi H, Bise T, Tanoue M. Prevalence of sarcopenia and its association with activities of daily living and dysphagia in convalescent rehabilitation ward inpatients. Clin Nutr. 2018;37:2022-2028. doi:10.1016/j.clnu.2017.09.009

36. Nagano A, Maeda K, Shimizu A, et al. Association of sarcopenic dysphagia with underlying sarcopenia following hip fracture surgery in older women. Nutrients. 2020;12. doi:10.3390/nu12051365

37. Sporns PB, Muhle P, Hanning U, et al. Atrophy of Swallowing Muscles Is Associated With Severity of Dysphagia and Age in Patients With Acute Stroke. J Am Med Dir Assoc. 2017;18:635.e1-635.e7. doi:10.1016/j.jamda.2017.02.002

38. Maeda K, Takaki M, Akagi J. Decreased Skeletal Muscle Mass and Risk Factors of Sarcopenic Dysphagia: A Prospective Observational Cohort Study. J Gerontol A Bio Sci Med Sci. 2017;72:1290-1294. doi:10.1093/gerona/glw190

39. Sjögren P. Hospitalisation associated with a deterioration in oral health. Evid Based Dent. 2011;12:48. doi:10.1038/sj.ebd.6400793

40. Abele-Horn M, Dauber A, Bauernfeind A, et al. Decrease in nosocomial pneumonia in ventilated patients by selective oropharyngeal decontamination (SOD). Intensive Care Med. 1997;23:187-195. doi:10.1007/s001340050314

41. Grap MJ, Munro CL, Ashtiani B, From SB. Oral Care Interventions in Critical Care: Frequency and Documentation. Am J Crit Care. 2003;12(2):113-119.

42. Wårdh I, Hallberg LR-M, Berggren U, Andersson L, Sörensen S. Oral Health Care-A Low Priority in Nursing. Scand J Caring Sci. 2000;14:137-142. doi:10.1111/j.1471-6712.2000.tb00574.x

43. Ajwani S, Jayanti S, Burkolter N, et al. Integrated oral health care for stroke patients a scoping review. J Clin Nurs. 2017;26:891-901. doi:10.1111/jocn.13520

44. Azarpazhooh A, Leake JL. Systematic Review of the Association Between Respiratory Diseases and Oral Health. J Periodontol. 2006;77:1465-1482. doi:10.1902/ jop.2006.060010

45. Sjögren P, Nilsson E, Forsell M, Johansson O, Hoogstraate J. A systematic review of the preventive effect of oral hygiene on pneumonia and respiratory tract infection in elderly people in hospitals and nursing homes: Effect estimates and methodological quality of randomized controlled trials. J Am Geriatr Soc. 2008;56:2124-2130. doi:10.1111/j.1532-5415.2008.01926.x

46. Ab. Malik N, Mohamad Yatim S, Hussein N, Mohamad H, McGrath C. Oral hygiene practices and knowledge among stroke-care nurses: A multicentre cross-sectional study. J Clin Nurs. 2018;27:1913-1919. doi:10.1111/jocn.14241

47. Murray J, Scholten I. An oral hygiene protocol improves oral health for patients in inpatient stroke rehabilitation. Gerodontology. 2018;35:18-24. doi:10.1111/ger.12309

48. Gondo T, Fujita K, Nagafuchi M, et al. The effect of preventive oral care on postoperative infections after head and neck cancer surgery. Auris Nasus Larynx. 2020;S0385-8146:30021-30023. doi:10.1016/j.anl.2020.01.001

49. Petersen PE, Yamamoto T. Improving the oral health of older people: The approach of the WHO Global Oral Health Programme. Community Dent Oral Epidemiol. 


\section{THE JOURNAL OF NUTRITION, HEALTH \& AGING}

2005·33:81-92 doi:10.1111/j.1600-0528.2004.00219.x

50. Shiraishi A, Yoshimura Y, Wakabayashi H, Tsuji Y. Poor oral status is associated with rehabilitation outcome in older people. Geriatr Gerontol Int. 2017;17:598-604. doi:10.1111/ggi.12763

51. Andersson P, Hallberg IR, Lorefält B, Unosson M, Renvert S. Oral health problems in elderly rehabilitation patients. Int J Dent Hyg. 2004;2:70-77. doi:10.1111/j.1601 5029.2004.00073.x

52. Hanne K, Ingelise T, Linda C, Ulrich PP. Oral status and the need for oral health care among patients hospitalised with acute medical conditions. J Clin Nurs. 2012;21:28512859. doi:10.1111/j.1365-2702.2012.04197.x

53. Yoshimura Y, Wakabayashi H, Bise T, et al. Sarcopenia is associated with worse recovery of physical function and dysphagia and a lower rate of home discharge in Japanese hospitalized adults undergoing convalescent rehabilitation. Nutrition. 2019;61:111-118. doi:10.1016/j.nut.2018.11.005

54. Wakabayashi H, Sakuma K. Rehabilitation nutrition for sarcopenia with disability: a combination of both rehabilitation and nutrition care management. J Cachexia Sarcopenia Muscle. 2014;5:269-277. doi:10.1007/s13539-014-0162-x

55. Matsuo H, Yoshimura Y, Ishizaki N, Ueno T. Dysphagia is associated with functional decline during acute-care hospitalization of older patients. Geriatr Gerontol Int 2017;17:1610-1616. doi:10.1111/ggi.12941

56. Morita K, Tsuka H, Kato K, et al. Factors related to masticatory performance in healthy elderly individuals. J Prosthodont Res. 2018;62:432-435. doi:10.1016/j. jpor.2018.03.007

57. Welmer AK, Rizzuto D, Parker MG, Xu W. Impact of tooth loss on walking speed decline over time in older adults: a population-based cohort study. Aging Clin Exp Res. 2017;29:793-800. doi:10.1007/s40520-016-0630-6

58. Sawa Y, Kayashita J, Nikawa H. Occlusal support is associated with nutritional improvement and recovery of physical function in patients recovering from hip fracture. Gerodontology. 2020;37:59-65. doi:10.1111/ger.12446

59. Wakabayashi H, Matsushima M, Ichikawa H, et al. Occlusal Support, Dysphagia Malnutrition, and Activities of Daily Living in Aged Individuals Needing Long-Term Care: A Path Analysis. J Nutr Health Aging. 2018;22:53-58. doi:10.1007/s12603-0170897-0

60. Baldini A, Beraldi A, Nota A, Danelon F, Ballanti F, Longoni S. Gnathologica postural treatment in a professional basketball player: a case report and an overview of the role of dental occlusion on performance. Ann Stomatol (Roma). 2012;3:51-58 PMCID: PMC3476490

61. Furuta M, Komiya-Nonaka M, Akifusa S, et al. Interrelationship of oral health status, swallowing function, nutritional status, and cognitive ability with activities of daily living in Japanese elderly people receiving home care services due to physical disabilities. Community Dent Oral Epidemiol. 2013;41(2):173-181. doi:10.1111/ cdoe. 12000

62. Kiesswetter E, Hengeveld LM, Keijser BJ, Volkert D, Visser M. Oral health determinants of incident malnutrition in community-dwelling older adults. J Dent. 2019;85:73-80. doi:10.1016/j.jdent.2019.05.017

63. Kiesswetter E, Keijser BJF, Volkert D, Visser M. Association of oral health with body weight: a prospective study in community-dwelling older adults. Eur J Clin Nutr. 2020;74:961-969. doi:10.1038/s41430-019-0536-4

64. Kikutani T, Enomoto R, Tamura F, Oyaizu K, Suzuki A, Inaba S. Effects of oral functional training for nutritional improvement in Japanese older people requiring long-term care. Gerodontology. 2006;23:93-98. doi:10.1111/j.17412358.2006.00104.x

65. McKenna G, Allen PF, Hayes M, DaMata C, Moore C, Cronin M. Impact of oral rehabilitation on the quality of life of partially dentate elders in a randomized controlled clinical trial: 2 year follow-up. PLoS One. 2018;13. doi:10.1371/journal. pone.0203349

66. Kim HJ, Lee JY, Lee ES, Jung HJ, Ahn HJ, Kim B Il. Improvements in oral function of elderly after simple oral exercise. Clin Interv Aging. 2019;14:915-924. doi:10.2147/ CIA.S205236
67. Peršić S, Čelebić A. Influence of different prosthodontic rehabilitation options on oral health-related quality of life, orofacial esthetics and chewing function based on patientreported outcomes. Qual Life Res. 2015;24:919-926. doi:10.1007/s11136-014-0817-2

68. Steele CM, Bayley MT, Peladeau-Pigeon M, et al. A Randomized Trial Comparing Two Tongue-Pressure Resistance Training Protocols for Post-Stroke Dysphagia. Dysphagia. 2016;31:452-461. doi:10.1007/s00455-016-9699-5

69. Park J-S, An D-H, Kam K-Y, Yoon T, Kim T, Chang M-Y. Effects of resistive jaw opening exercise in stroke patients with dysphagia: A double- blind, randomized controlled study. J Back Musculoskelet Rehabil. 2019;33:1-7. doi:10.3233/bmr181477

70. Cho YS, Oh DH, Paik YR, Lee JH, Park JS. Effects of bedside self-exercise on oropharyngeal swallowing function in stroke patients with dysphagia: A pilot study. J Phys Ther Sci. 2017;29:1815-1816. doi:10.1589/jpts.29.1815

71. Choi J-B, Shim S-H, Yang J-E, Kim H-D, Lee D-H, Park J-S. Effects of Shake exercise in stroke survivors with oropharyngeal dysphagia. NeuroRehabilitation. 2017;41:753-757. doi:10.3233/NRE-172145

72. Park JS, Hwang NK, Oh DH, Chang MY. Effect of head lift exercise on kinematic motion of the hyolaryngeal complex and aspiration in patients with dysphagic stroke. J Oral Rehabil. 2017;44:385-391. doi:10.1111/joor.12492

73. Sakayori T, Maki Y, Hirata S, Okada M, Ishii T. Evaluation of a Japanese "Prevention of Long-term Care" project for the improvement in oral function in the high-risk elderly. Geriatr Gerontol Int. 2013;13:451-457. doi:10.1111/j.1447-0594.2012.00930.x

74. Ibayashi H, Fujino Y, Pham TM, Matsuda S. Intervention study of exercise program for oral function in healthy elderly people. Tohoku J Exp Med. 2008;215:237-245. doi:10.1620/tjem.215.237

75. Cho EP, Hwang SJ, Clovis JB, Lee TY, Paik D Il, Hwang YS. Enhancing the quality of life in elderly women through a programme to improve the condition of salivary hypofunction. Gerodontology. 2012;29:e972-980. doi:10.1111/j.17412358.2011.00594.x

76. Hakuta C, Mori C, Ueno M, Shinada K, Kawaguchi Y. Evaluation of an ora function promotion programme for the independent elderly in Japan. Gerodontology. 2009;26:250-258. doi:10.1111/j.1741-2358.2008.00269.x

77. Iwao Y, Shigeishi H, Takahashi S, Uchida S, Kawano S, Sugiyama M. Improvement of physical and oral function in community-dwelling older people after a 3-month long-term care prevention program including physical exercise, oral health instruction, and nutritional guidance. Clin Exp Dent Res. 2019;5:611-619. doi:10.1002/cre2.226

78. Miyoshi S, Shigeishi H, Fukada E, Nosou M, Amano H, Sugiyama M. Association of Oral Function With Long-Term Participation in Community-Based Oral Exercise Programs in Older Japanese Women: A Cross-Sectional Study. J Clin Med Res. 2019;11:165-170. doi:10.14740/jocmr3664

79. Wakabayashi H. Medical-dental collaboration in general and family medicine. J Gen Fam Med. 2019;20:47. doi:10.1002/jgf2.237

80. Barnett T, Hoang H, Stuart J, Crocombe L. Non-dental primary care providers' views on challenges in providing oral health services and strategies to improve oral health in Australian rural and remote communities: A qualitative study. BMJ Open. 2015;5:e009341. doi:10.1136/bmjopen-2015-009341

81. Lalla E, Papapanou PN. Diabetes mellitus and periodontitis: A tale of two common interrelated diseases. Nat Rev Endocrinol. 2011;7:738-748. doi:10.1038/ nrendo.2011.106

82. Sippli K, Rieger MA, Huettig F. GPs' and dentists' experiences and expectations of interprofessional collaboration: Findings from a qualitative study in Germany. BMC Health Serv Res. 2017;17. doi:10.1186/s12913-017-2116-4

83. Shiraishi A, Yoshimura Y, Wakabayashi H, Tsuji Y, Yamaga M, Koga H. Hospital dental hygienist intervention improves activities of daily living, home discharge and mortality in post-acute rehabilitation. Geriatr Gerontol Int. 2019;19:189-196. doi:10.1111/ggi.13583

84. Suzuki R, Nagano A, Wakabayashi H, et al. Assignment of Dental Hygienists Improves Outcomes in Japanese Rehabilitation Wards: A Retrospective Cohort Study. J Nutr Health Aging. 2020;24:28-36. doi:10.1007/s 12603-019-1284-9 